\title{
Effect of gga-miR-155 on cell proliferation, apoptosis and invasion of Marek's disease virus (MDV) transformed cell line MSB1 by targeting RORA
}

\author{
Ke Ding, Zu-Hua Yu*, Chuan Yu, Yan-Yan Jia, Lei He, Cheng-Shui Liao, Jing Li, Chun-Jie Zhang, Yin-Ju Li, \\ Ting-Cai Wu, Xiang-Chao Cheng, Zi-Yu Zhou and Zu-Ling Yu
}

\begin{abstract}
Background: Marek's disease (MD) is caused by the oncogenic Marek's disease virus (MDV), and is a highly contagious avian infection with a complex underlying pathology that involves lymphoproliferative neoplasm formation. MicroRNAs (miRNAs) act as oncogenes or tumor suppressors in most cancers. The gga-miR-155 is downregulated in the MDV-infected chicken tissues or lymphocyte lines, although its exact role in tumorigenesis remains unclear. The aim of this study was to analyze the effects of gga-miR-155 on the proliferation, apoptosis and invasiveness of an MDV-transformed lymphocyte line MSB1 and elucidate the underlying mechanisms.

Results: The expression level of gga-miR-155 was manipulated in MSB1 cells using specific mimics and inhibitors. While overexpression of gga-miR-155 increased proliferation, decreased the proportion of G1 phase cells relative to that in $\mathrm{S}$ and $\mathrm{G} 2$ phases, reduced apoptosis rates and increased invasiveness. However, its downregulation had the opposite effects. Furthermore, gga-miR-155 directly targeted the RORA gene and downregulated its expression in the MSB1 cells.

Conclusion: The gga-miR-155 promotes the proliferation and invasiveness of the MDV-transformed lymphocyte line MSB1 and inhibits apoptosis by targeting the RORA gene.
\end{abstract}

Keywords: Gga-miR-155, Marek's disease, MSB1, Lymphocyte line, Proliferation, Apoptosis, RORA

\section{Background}

Marek's disease virus (MDV) is an oncogenic herpesvirus, reclassified as the Gallid alphaherpesvirus 2 (GaHV2) [1]. It is the causative agent of Marek's disease (MD), which is characterized by complex clinical syndromes, including immune suppression, paralysis, neurological signs and lesions, and the rapid formation of $\mathrm{CD} 4^{+} \mathrm{T}$-cell lymphomas [2-4], and is responsible for considerable losses to the poultry industry worldwide. Although a vaccine is available against MD, eruptions are common even in immunized chicken flocks, likely due to intensive farming, incomplete immunization and increasing virulence [5-8]. Therefore, it

\footnotetext{
* Correspondence: yzhd05@163.com

Key Laboratory of Animal Disease and Public Health, Henan University of Science and Technology, Luoyang 471003, People's Republic of China
}

is essential to determine the molecular mechanisms underlying MDV-induced oncogenesis.

MicroRNAs (miRNAs) are endogenous small noncoding RNA that degrade mRNAs or inhibit translation by binding to their $3^{\prime}$-untranslated regions (3'-UTR), and therefore regulate multiple cellular processes, such as proliferation, cell cycle, apoptosis, migration and metabolism [9-13]. Recent studies have identified several host and viral miRNAs that potentially regulate MDVinduced tumorigenesis [14-17]. MiRNA-155 is a conserved multifunctional cellular miRNA that regulates the proliferation, migration and invasive growth of tumor cells, and is therefore closely associated with tumor initiation and progression [18-21], Studies show that the MD-encoded miR-M4-5p is the viral ortholog of cellular miR-155, and shares common targets with miR-155 and

(c) The Author(s). 2020 Open Access This article is distributed under the terms of the Creative Commons Attribution 4.0 International License (http://creativecommons.org/licenses/by/4.0/), which permits unrestricted use, distribution, and reproduction in any medium, provided you give appropriate credit to the original author(s) and the source, provide a link to the Creative Commons license, and indicate if changes were made. The Creative Commons Public Domain Dedication waiver (http://creativecommons.org/publicdomain/zero/1.0/) applies to the data made available in this article, unless otherwise stated. 
is involved in MD lymphomagenesis [16, 17, 22, 23]. Zhao et al. have implicated the critical role of MDVmiR-M4 in the induction of tumors, demonstrated the similarities function of both orthologs [24]. However, recent studies on MDV-transformed cell lines suggest that continued expression of miR-M4 is not essential to maintain the transformed phenotype [25, 26].

MDV-miR-M4 is highly expressed in virus-infected CEFs, MDV-induced tumor tissues, lymphoblastoid cell lines and serum exosomes $[4,27,28]$, and promotes MDV tumorigenesis. In contrast, miR-155, gga-miR-181a and gga-miR-26a are downregulated in MDV-transformed $\mathrm{T}$ lymphocyte lines, MDV-induced tumors and MDV-infected peripheral blood lymphocytes $[29,30]$. Low levels of gga-miR-26a and gga-miR-181a have been associated with suppression of MDV-induced tumors [31]. MDV-miR-M4 is known to complement miR-155 in initiating $\mathrm{MD}$ lymphomas, although the underlying mechanisms, especially the role of host miRNAs, have not completely elucidated. The exact biological relevance of gga-miRNA-155 in MD tumorigenesis needs to be confirmed. To this end, we overexpressed and inhibited gga-miR-155 in an MDV-transformed cell line using mimics and inhibitors respectively, and analyzed their growth, proliferation, apoptosis and invasiveness to explore the possible role of gga-miR-155 in MDV-mediated tumorigenesis. Furthermore, we predicted and demonstrated that Retinoid Acid Receptor-Related Orphan Receptor Alpha (RORA) is one of the targets of gga-miR-155, and the gga-miR-155 regulated the proliferation, cell cycle, apoptosis and invasiveness of MSB1 cells by targeting RORA.

\section{Results}

Gga-miR-155 promotes the proliferation and cell cycle progression of MSB1 cells

To determine the role of gga-miR-155 in MDVtransformed $\mathrm{T}$ cells, we respectively overexpressed and downregulated the miRNA in MSB1 cells using mimics and inhibitors (Fig. 1). While high levels of gga-miR-155 enhanced the proliferative capacity of the MSB1 cells compared to the controls $(P<0.05)$, its downregulation had the opposite effects $(\mathrm{P}<0.05)$ (Fig. 2). Furthermore, analysis of the cell cycle distribution showed that the proportion of cells in the G1 phase decreased significantly in the gga-miR-155 mimics group compared to the respective control, and that in the S and G2 phases increased. Upon gga-miR-155 inhibition however, the cells accumulated in the G1 phase, with a concomitant decrease in the proportion of cells in the $\mathrm{S}$ and $\mathrm{G} 2$ phases $(p<0.05)$ (Fig. 3). Consistent with these results, gga-miR-155 accelerated MSB1 cell proliferation and cell cycle progression.

\section{Gga-miR-155 inhibits apoptosis of MSB1 cells}

To determine the effect of gga-miR-155 on apoptosis, the percentage of apoptotic MSB1 cells was evaluated $48 \mathrm{~h}$ after transfecting with the different constructs. The proportion of apoptotic cells was significantly lower among those transfected with gga-miR-155 mimics compared to the control. Furthermore, the gga-miR-155 inhibitor significantly increased the proportion of apoptotic cells compared to the inhibitor NC $(P<0.05$,
A

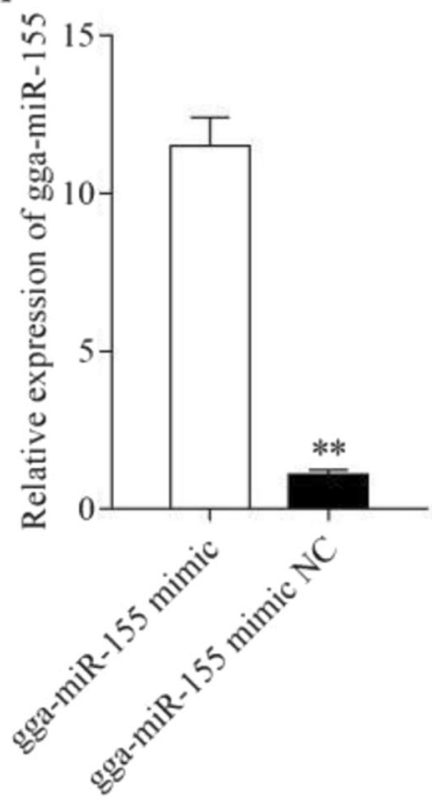

B

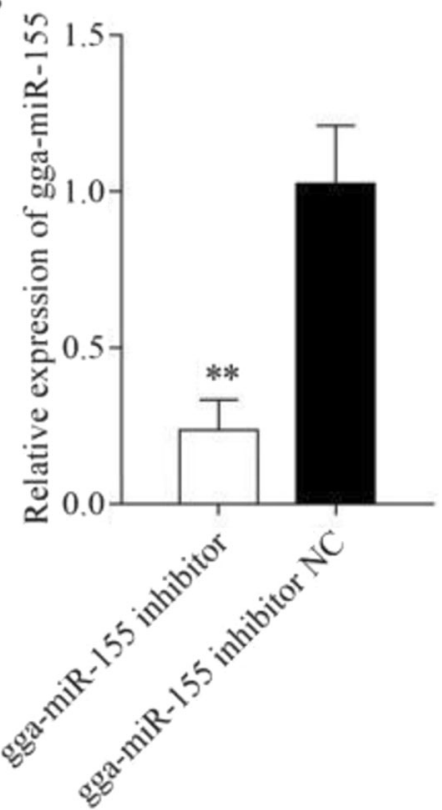

Fig. 1 The expression levels of gga-miR-155 in MSB1 cells transfected with (a) gga-miR-155 mimic and (b) gga-miR-155 inhibitor. ** $P<0.01$, * $P<0.05$ 

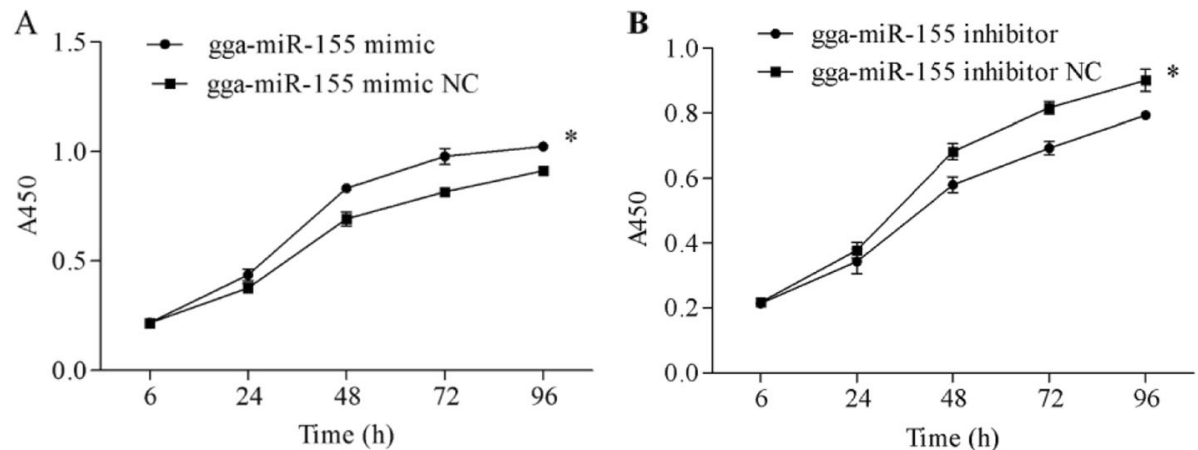

Fig. 2 gga-miR-155 promoted proliferation of MSB1 cells Time-dependent growth curve of MSB1 cells transfected with (a) gga-miR-155 mimic and (b) gga-miR-155 inhibitor and their respective controls. ${ }^{*} P<0.05$ versus control

Fig. 4). These results indicated that gga-miR-155 can inhibit apoptosis of MSB1 cells.

\section{Gga-miR-155 promotes migration and invasion of MSB1 cells}

The migration and invasiveness of MSB1 cells were also assessed following transfection with the different constructs. As shown in Fig. 5, overexpression of gga-miR155 slightly increased the migration capacity of the MSB1 cells $(P>0.05)$, while the gga-miR-155 inhibitor significantly decreased the proportion of migrating cells $(P<0.05$, Fig. 5a). Furthermore, the invasive capacity of MSB1 cells transfected with gga-miR-155 mimics was notably increased $(P<0.05)$, and that of cells transfected with gga-

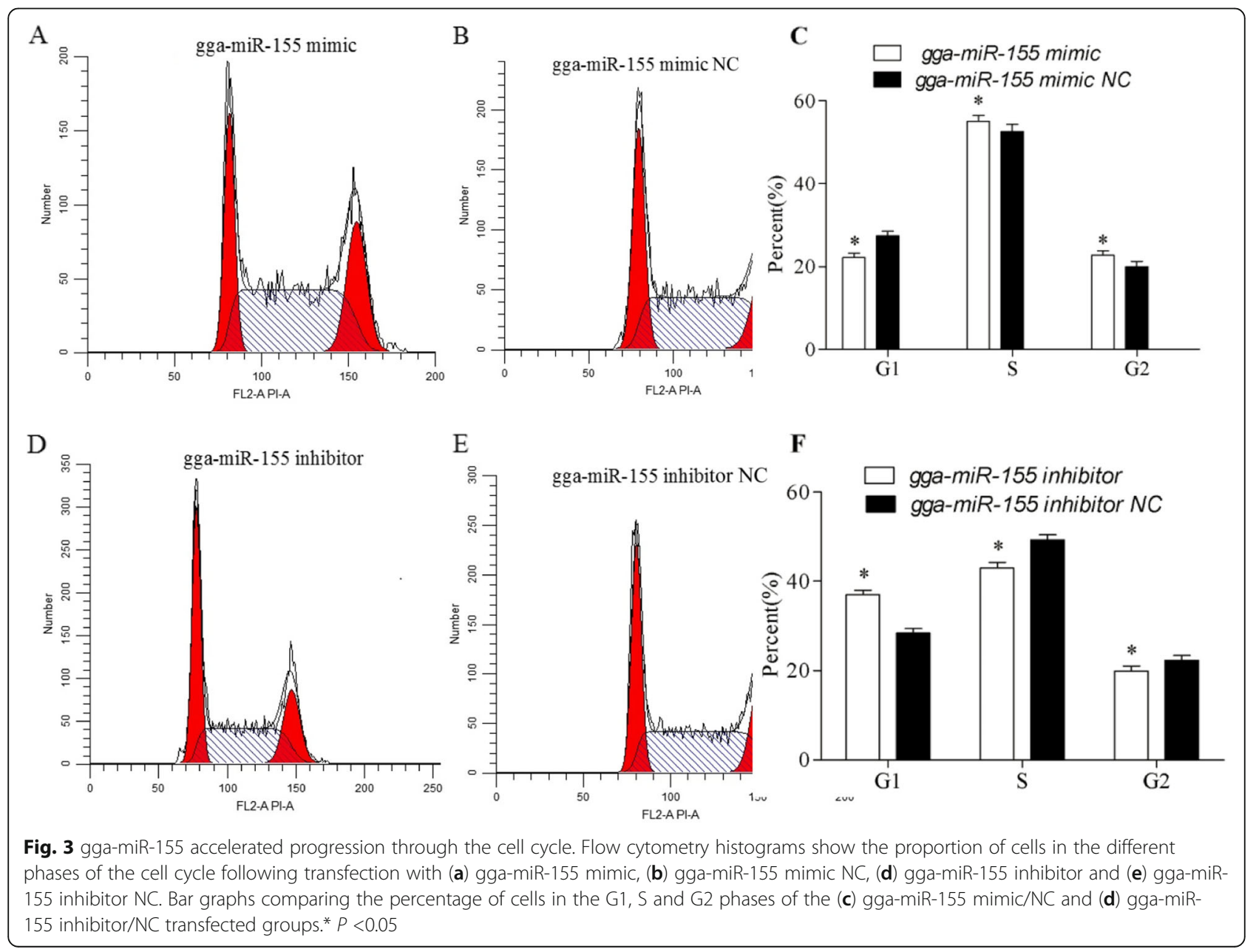



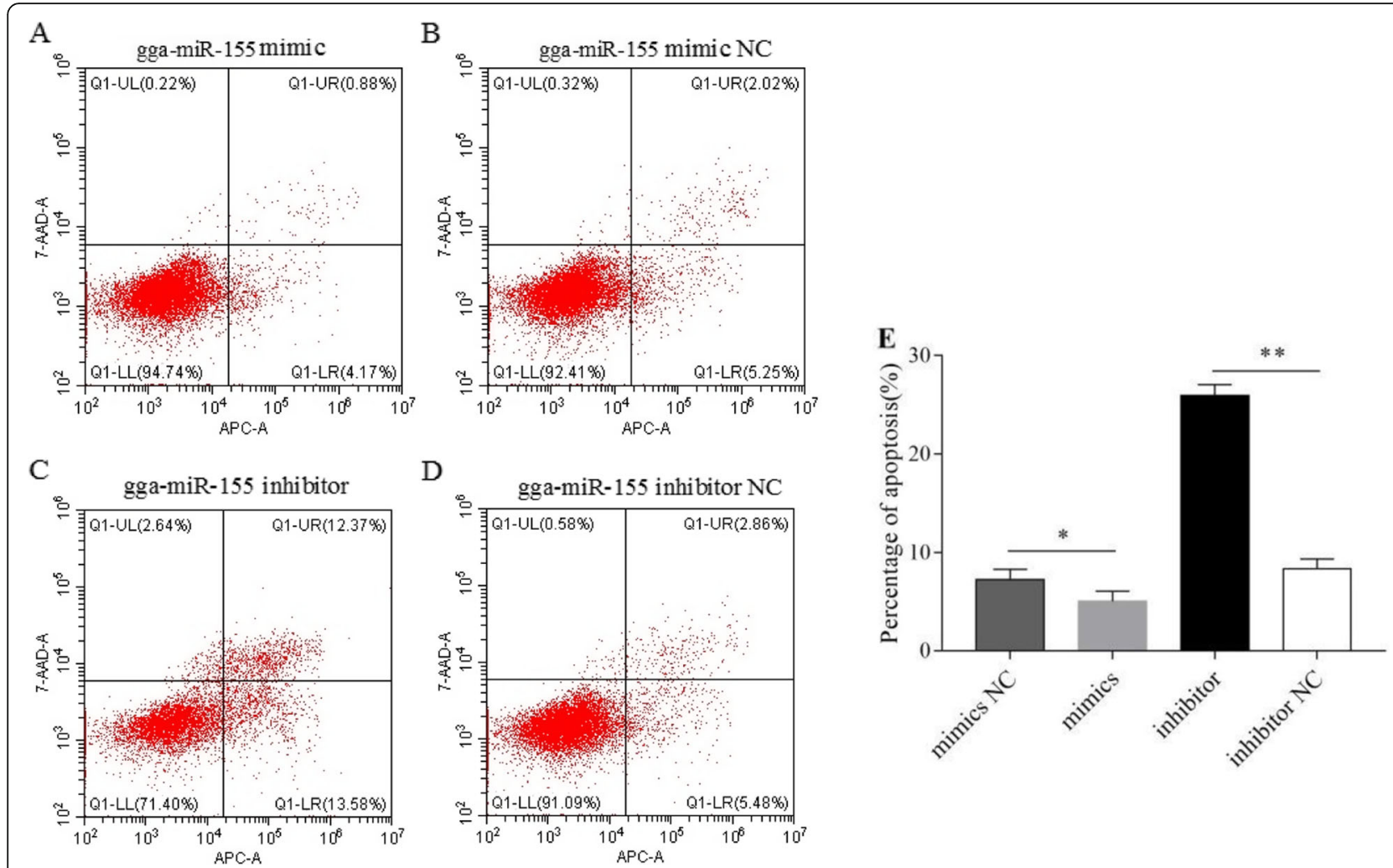

Fig. 4 gga-miR-155 blocked apoptosis in MSB1 cells. Flow cytometry dot plots showing the percentage of live and apoptotic cells in the (a) gga-miR-155 mimic, (b) gga-miR-155 mimic NC, (c) gga-miR-155 inhibitor and (d) gga-miR-155 inhibitor NC groups. (e) Percentage of apoptotic cells in the different groups. * $P<0.05$

miR-155 inhibitors was significantly decreased $(\mathrm{P}<0.05$, Fig. 5b). Thus, gga-miR-155 also promotes the migration and invasion of MDV-transformed cells.

\section{Gga-miR-155 suppresses RORA expression by binding to its 3' UTR sequence}

Previous studies have identified the tumor suppressor RORA as a putative target of miR-155 [32]. To validate this surmise, we screened for the putative target genes of
miR-155 using TargetScan (release 6.2, http://www.targetscan.org/) (Fig. 6a). The direct binding of gga-miR155 to the 3'-UTR of the chicken RORA gene was assessed by the dual luciferase reporter assay (DLRA). Briefly, HEK293T cells were transfected with pYrMirTarget-RORA 3'-UTR with or without the gga-miR155 mimics or gga-miR-155 inhibitors. As shown in Fig. $6 \mathrm{~b}$, the relative luciferase activity of the reporter significantly decreased in the presence of gga-miR-155
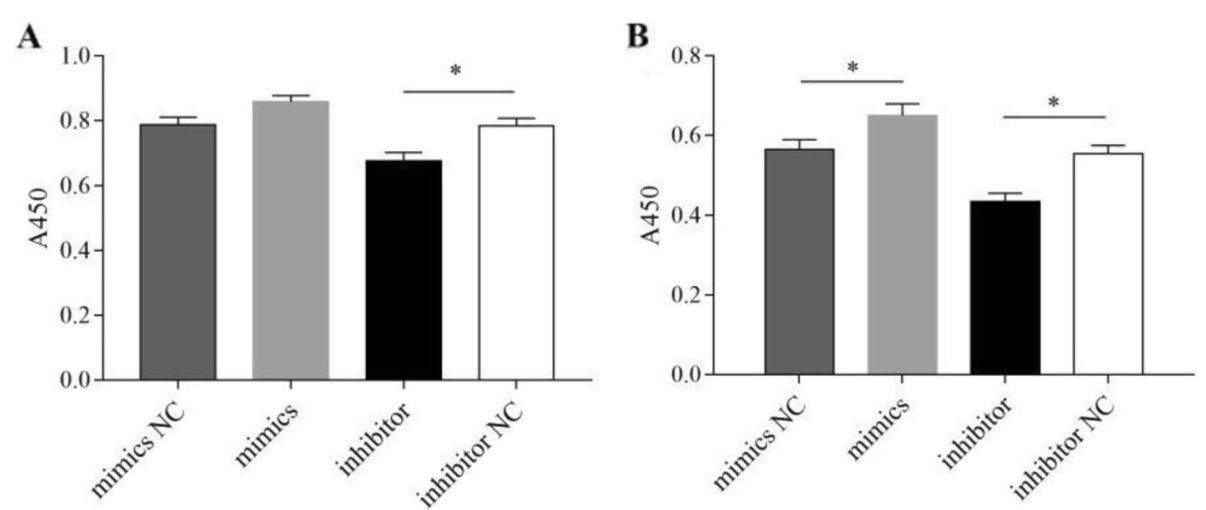

Fig. 5 Effects of gga-miR-155 on the migrate and invasion of MSB1 cells. Bar graphs showing the migration and invasion rates of MSB1cells transfected with (a) The migration of MSB1 cell treated with gga-miR-155 mimic/NC \&inhibitor/NC (b) The invasion of MSB1 cell treated with gga-miR-155 mimic/NC \&inhibitor/NC * $P<0.05$ 


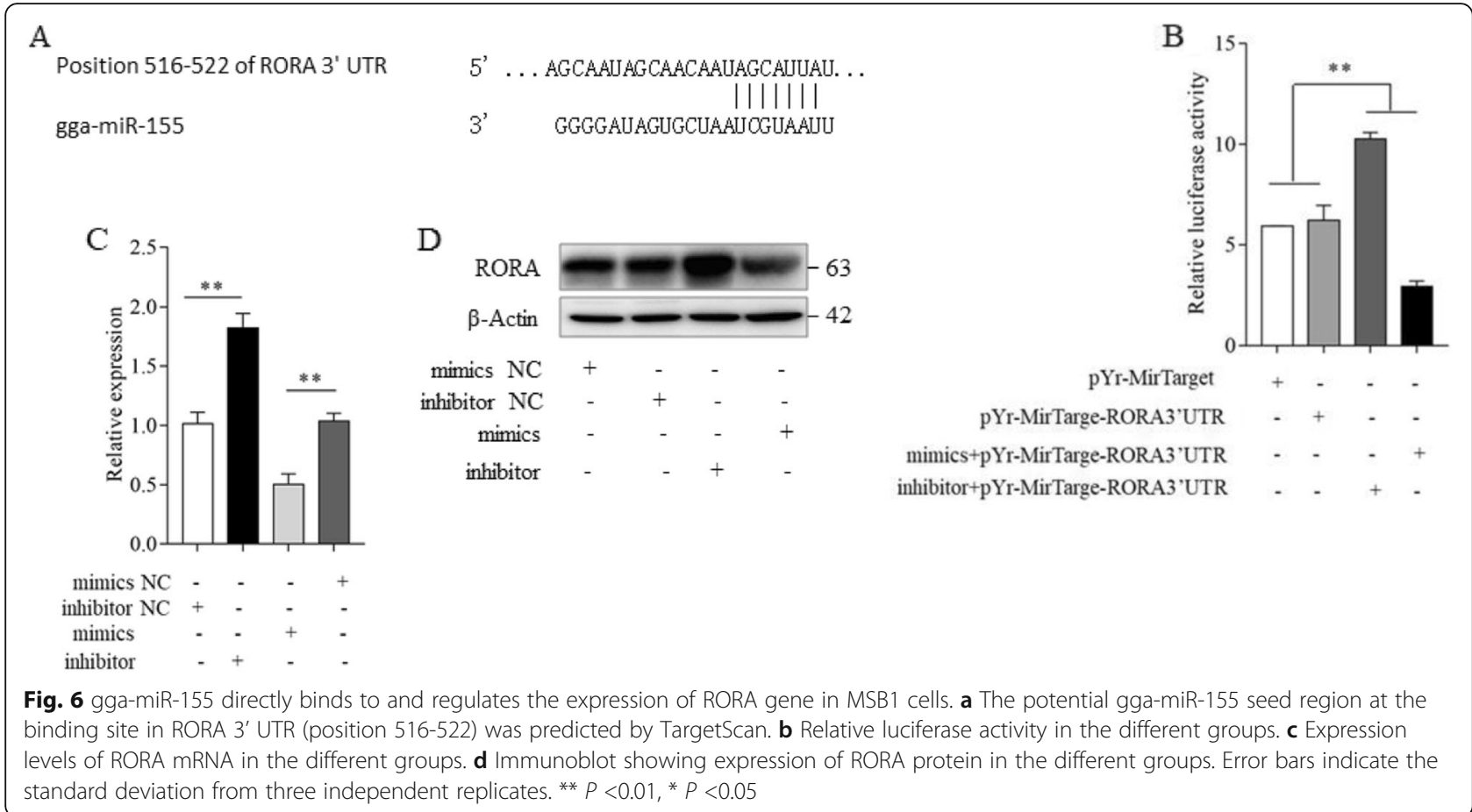

mimics and increased when co-transfected with ggamiR-155 inhibitor. we next determined whether altering the expression levels of gga-miR-155 affected that of RORA in the MSB1 cells. In agreement with our hypothesis, RORA mRNA (Fig. 6c) and protein (Fig. 6d) levels respectively decreased and increased in the cells transfected with gga-miR-155 mimic and gga-miR-155 inhibitor. Therefore, gga-miR-155 suppresses RORA both transcriptionally and post-transcriptionally in the MSB1 cells. Taken together, the RORA gene is a putative target gene of gga-miR-155, which binds to the former's 3'-UTR region.

\section{Discussion}

MicroRNAs are conservative, single-stranded noncoding small molecular RNA 22-25 nucleotides long, with a characteristic hairpin structure that is synthesized by the RNA endonucleases Drosha and Dicer. The 5'terminal seed sequences of mature miRNAs regulate target gene expression at the post-transcriptional level by binding to the 3'-UTR of the target mRNAs, which results in their degradation or translational suppression $[29,33]$. The biological role of miRNAs has gained considerable attention in recent years, and several have been identified as oncogenes or tumor suppressor genes that regulate proliferation, differentiation, apoptosis and migration of cancer cells [34, 35]. Therefore, miRNAs are potential markers for the diagnosis, prognosis, classification, staging and therapeutic monitoring of cancers. MiRNA-155 for instance is associated with the occurrence and development of renal cancer [36], glioma [37], lung cancer [38], colon cancer [39, 40] and other malignancies [41-44].

To elucidate the role of miR-155 in the MDVtransformed cells, we manipulated its expression levels using specific mimics and inhibitors. Overexpression of gga-miR-155 significantly increased the proliferation of MSB1 cells, accelerated progression through the cell cycle, decreased apoptosis, and promoted their migration and invasiveness in vitro. Not surprisingly, downregulating gga-miR-155 had the opposite effects. These findings are interesting considering the fact that although gga-miR-155 was down-regulated in MDV transformed $\mathrm{T}$ lymphocyte lines, spleen tumor tissues and liver lymphoma after MDV infection, it could promote proliferation, migration and invasiveness of MSB1 cells and inhibit apoptosis.

Retinoid acid receptor-related orphan receptor alpha (RORA) is a member of the nuclear receptor protein superfamily that regulates circadian rhythm regulator, metabolism, immune responses and inflammatory diseases $[45,46]$. It is also a tumor suppressor and therefore inactivated during malignant transformation, and tumor initiation and metastasis [47, 48]. Several targets of miRNA-155 have been identified in recent years, such as the BRG1 [49] and FOXO3a [50] in lymphoma, and SOCS1 in severe acute pancreatitis [51]. Parnas et al. predicted 9 common target genes of MDV1-miR-M4, KSHV-miR-K11 and HAS-miR-155, and 4 of MDV1miR-M4 and HAS-miR-155 in human B cells and 
Table 1 Sequences of primers used for qRT-PCR assays

\begin{tabular}{ll}
\hline Name & Primer Sequences $\left(5^{\prime} \rightarrow 3^{\prime}\right)$ \\
\hline U6 RT prime & GTCGTATCCAGTGCAGGGTCCGAGGTATTCGCACTGGATACGACCGATACA \\
U6 Forward primer & CGCTTCGGCAGCACATATAC $-3^{\prime}$ \\
gga-miR-155 RT prime & GTCGTATCCAGTGCAGGGTCCGAGGTATCGCACTGGATACGACCCCCTATC \\
gga-miR-155 Forward primer & TGCGCTTAATGCTAATCGTGAT \\
gga-miR-155/U6 Reverse primer & CCAGTGCAGGGTCCGAGGTATT \\
gga - $\beta$-actin Forward primer & AGAAGGAGATCACAGCCCT \\
ggaß-actin Reverse primer & GGGTCCGGATTCATCGTACT \\
RORA Forward primer & GACCTCTCCAACTGTGTCCA \\
RORA Reverse primer & GCCACATTACCTCCCTTGC \\
\hline
\end{tabular}

chicken $\mathrm{T}$ cells, which includes RORA [32]. In the present study also, we identified RORA as one of the putative targets of gga-miRNA-155 through bioinformatics analysis. Furthermore, luciferase reporter assay revealed that gga-miR-155 could directly target the 3 '-UTR of RORA. Taking together all these findings, we can conclude that RORA is a direct target of gga-miR-155 in MDV-induced tumorigenesis.

\section{Conclusions}

The gga-miRNA-155 promotes proliferation, migration and invasiveness of MSB1 cells and inhibits their apoptosis via RORA by targeting the latter's 3'-UTR region. Since this contradicts the role of other miRNAs that are downregulated during MD tumorigenesis, it remains to be elucidated whether the low expression level of ggamiRNA-155 in MD tumor cells or tissues is correlated to other non-coding RNAs.

\section{Methods}

\section{Cell culture and transfection}

The MDV-transformed chicken lymphoblastoid cell line MDCC-MSB1 was purchased from Shanghai Kindu Biotechnology Co. Ltd. The cells were cultured at $37^{\circ} \mathrm{C}$ under $5 \% \mathrm{CO}_{2}$ in RPMI 1640 medium (Gibco, USA) supplemented with $10 \%$ fetal calf serum (Gibco, USA), $10 \%$ tryptose phosphate broth (Sigma, USA) and 1\% penicillin-streptomycin solution (HyClone, USA). The gga-miR-155 mimic, gga-miR-155 inhibitor and their respective negative controls were synthesized by RiboBio Corporation (China). The constructs were transfected using FuGENE ${ }^{\ominus}$ HD (Promega, USA) according to the manufacturer's instructions. Briefly, the cells were seeded in 6 -well plates at the density of $3 \times 10^{5}$ per well, and transfected with $50 \mathrm{nM}$ gga-miR-155 mimic or 200 $\mathrm{nM}$ gga-miR-155 inhibitor and their respective controls (NC). The transfection efficiency was validated after $48 \mathrm{~h}$ by RT-qPCR.

\section{Stem-loop quantitative real- time PCR (qRT- PCR)}

Total RNA was extracted from the cultured cells using TRIzol reagent (Invitrogen, USA) according to the manufacturer's protocol, and quantified using the NanoDrop ND-2000 Spectrophotometer (Thermo, USA). Reverse transcription was performed using the miRNA-specific stem-loop reverse-transcription primer (Sangon, Shanghai, China) using $1 \mu \mathrm{g}$ total RNA. Real time qPCR was performed using miScript SYBR Green PCR kit (Qiagen, USA) in the ABI 7900 PCR Detection System (Applied Biosysterm, USA). The cycling parameters were as follows: $50{ }^{\circ} \mathrm{C}$ for $2 \mathrm{~min}, 95^{\circ} \mathrm{C}$ for $10 \mathrm{~min}$, and 40 cycles of $95^{\circ} \mathrm{C}$ for $30 \mathrm{~s}$ and $60^{\circ} \mathrm{C}$ for $1 \mathrm{~min}$. The relative target gene expression $\left(2^{-\Delta \Delta \mathrm{Ct}}\right)$ was normalized to that of U6 endogenous small nuclear RNA. The primer sequences are shown in Table 1.

\section{Target genes prediction and luciferase reporter assay}

The target genes of gga-miR-155 were predicted using the online tools TargetScan (http://www.targetscan.org) and miRDB (http://mirdb.org/miRDB/). RORA 3'-UTR sequences containing the putative gga-miR-155 binding sites were amplified and cloned into the pYr-MirTarget luciferase reporter vector. The primers used are listed in Table 2. HEK293T cells in the logarithmic growth phase were seeded into 12 -well plates and cultured overnight, and co-transfected with the RORA 3'-UTR reporter vector and gga-miR-155 mimics or gga-miR-155 inhibitor using Lipofectamine ${ }^{\mathrm{TM}}$ 2000. Luciferase activity was

Table 2 Sequences of primers used for amplification of RORA 3'-UTR

\begin{tabular}{lr}
\hline Name & Primer Sequences $\left(5^{\prime} \rightarrow 3^{\prime}\right)$ \\
\hline RORA3'-UTR Forward primer & TAGGCGATCGCTCGAGCATTGTTTCATGAAGGACGAT \\
RORA 3'-UTR Reverse primer & TAGGCGATCGCTCGAGCATTGTTTCATGAAGGACGAT \\
\hline
\end{tabular}


measured $48 \mathrm{~h}$ after co-transfection using the Double Luciferase Reporter Gene Assay kit (Promega) according to the manufacturer's instructions. The ratio of renilla and firefly luciferase intensities was calculated. The assay was performed thrice.

\section{Western blotting}

Total proteins were extracted from MSB1 cells $48 \mathrm{~h}$ post-transfection using radio immunoprecipitation assay (RIPA) lysis buffer supplemented with protease and phosphatase inhibitors. The concentration of proteins was determined by the BCA assay (BCA Protein Assay Kit, Beyotime, Shanghai, China), and $20 \mu \mathrm{g}$ protein per sample was denatured in loading buffer by boiling for $3 \sim 5 \mathrm{~min}$, and separated by $10 \%$ SDS-PAGE. The resulting bands were electro-transferred to polyvinylidene difluoride (PVDF) membrane at $100 \mathrm{~mA}$ over $1.5 \mathrm{~h}$. After blocking with $4 \%$ BSA for $1 \mathrm{~h}$, the membranes were incubated overnight with primary antibodies against RORA (1:1000, Abcam, ab60134) and $\beta$-actin (1:1000, Abcam, ab8226), followed by HRP-conjugated antirabbit IgG (1:1000) and anti-mouse IgG (1:1000) (Bayotime) respectively. The positive proteins bands were detected using a chemiluminescence system (Bio-Rad Clarity Western ECL; Bio-Rad Laboratories Inc.), and the grayscale values were quantified using ImageJ. The density of the RORA bands was standardized to that of $\beta$-actin.

\section{Cell proliferation assay}

Suitably transfected MSB1 cells were harvested after $6 \mathrm{~h}$, and seeded into 96-well plates at the density of 4000 cells/well. Twenty microliters of the Cell Counting Kit 8 reagent (CCK 8, Biosharp Biotech, China) was added to each well after 6, 24, 48, 72 and $96 \mathrm{~h}$ of culture, and the optical density (OD) was measured at $450 \mathrm{~nm}$ using an ELISA reader (Thermo, USA) following a $4 \mathrm{~h}$ incubation.

\section{Cell cycle assay}

The cell cycle profile was analyzed using the Cell Cycle Detection Kit (KeyGen, China) according to the manufacturer's instructions. Briefly, the cells harvested $48 \mathrm{~h}$ after transfection were washed twice with cold PBS, and re-suspended in $100 \mu \mathrm{l}$ PBS. After fixing with $70 \%$ icecold ethanol for $4 \mathrm{~h}$ at $4{ }^{\circ} \mathrm{C}$, the cells were rinsed twice with cold PBS, incubated with $100 \mu \mathrm{l}$ RNase $(50 \mu \mathrm{g} / \mathrm{mL}$; Sigma, USA) for $30 \mathrm{~min}$ at $37^{\circ} \mathrm{C}$, and finally stained with $400 \mu \mathrm{l} \mathrm{PI}(50 \mu \mathrm{g} / \mathrm{ml})$ in the dark at $4{ }^{\circ} \mathrm{C}$ for $30 \mathrm{~min}$. The stained cells were analyzed by flow cytometry (BD bioscience, USA). Each sample was tested in triplicates.

\section{Cell migration and invasion assay}

The in vitro migration and invasion of MSB1 cells were analyzed $48 \mathrm{~h}$ after transfection using the transwell method. For the migration assay, RPMI 1640 medium containing 10\% FBS was dispensed into the lower chambers of transwell inserts ( $8 \mu \mathrm{m}$ pore size; Corning 3422, USA) placed in a 24-well plate. After $1 \mathrm{~h}, 200 \mu \mathrm{L}$ of the cell suspension $\left(6 \times 10^{5} \mathrm{cell} / \mathrm{ml}\right)$ in serum free RMPI 1640 was seeded in the upper chambers of each insert. After incubating the cells for $24 \mathrm{~h}$ at $37^{\circ} \mathrm{C}$ under $5 \%$ $\mathrm{CO}_{2}$, the transwells were removed, and $60 \mu \mathrm{L}$ CCK- 8 reagent (Biosharp Biotech, China) was added to each well. The viability of the migrated cells was assessed as already described. The invasiveness of MSB1 was assayed as above, except that the seeding density of the cells was $1 \times 10^{5}$ /well, and the upper chambers were pre-coated with Matrigel (BD Bioscience, USA). Each sample was tested in triplicates.

\section{Annexin/7-AAD staining}

Apoptosis in the MSB1 cells was evaluated by AnnexinV-APC/7-AAD staining and flow cytometry (CytoFLEX; Beckman Coulter Inc., USA). Transfected cells were harvested after $48 \mathrm{~h}$, washed twice with cold PBS, and stained using the AnnexinV-APC/7-AAD Cell Apoptosis Detection kit (NanJing KeyGen Biotech Co., Ltd., China) according to the manufacturer's instructions. The cells were resuspended in $500 \mu \mathrm{l}$ binding buffer,and incubated with $5 \mu \mathrm{L}$ each of AnnexinV-APC and 7-AAD for $15 \mathrm{~min}$ in the dark at room temperature. The stained samples were analyzed by flow cytometry, and the percentage of apoptotic cells was calculated.

\section{Statistical analysis}

SPSS 19.0 and GraphPad Prism (Version 6.0) were used for data analysis. Data were expressed as mean \pm SD. Two groups were compared using Student's t-test, and multiple groups with the one-way ANOVA and LSD tests. $P$ values $<0.05$ were considered statistically significant.

\section{Abbreviations}

DMEM: Dulbecco's modified Eagle's medium; DMSO: Dimethyl sulfoxide; FBS: Fetal bovine serum; MD: Marek's disease; MDV: Marek's disease virus; miRNAs: Micrornas; qRT-PCR: Quantitative Real-time Polymerase Chain Reaction; SDS-PAGE: Sodium dodecyl sulfate polyacrylamide gel electrophoresis; TPB: Tryptose phosphate broth; UTR: Untranslated region.; RORA: Retinoid acid-related orphan receptor $\mathrm{A}$

\section{Acknowledgments}

Not applicable.

\section{Authors' contributions}

$\mathrm{KD}$ and $\mathrm{ZHY}$ designed the experiments, created the figures and wrote the manuscript. CY, YYJ, ZLY and LH conducted most of the experiments and analyzed the results. CSL and ZYZ performed the dual luciferase reporter assay, and $J \mathrm{~L}$ conducted cell culture. CJZ, YJL and TCW helped with result analysis. XCC revised the manuscript. All authors read and approved the final manuscript. 


\section{Funding}

The research was supported by the National Natural Science Foundation of China (31702207), the National Natural Science Foundation Henan Joint Fund (U1504308), and the provincial-level Science and Technology Innovation Platform Cultivation Project of the Henan University of Science and Technology (2015SPT004). The funding body has not participated in the research design, collection, analysis, interpretation of data and writing the manuscript.

\section{Availability of data and materials}

The datasets used and/or analyzed during the current study are available from the corresponding author on reasonable request.

\section{Ethics approval and consent to participate}

Experimental procedures involving animals were performed in compliance with the institutional and national guidelines and were approved by the Animal Care and Use Committee of Henan Province (China).

\section{Consent for publication}

Not applicable.

\section{Competing interests}

The authors declare that they have no competing interests.

Received: 23 September 2019 Accepted: 9 January 2020

Published online: 28 January 2020

\section{References}

1. Davison AJ, Eberle R, Ehlers B, Hayward GS, Mcgeoch DJ, Minson AC, Pellett PE, Roizman B, Studdert MJ, Thiry E. The order Herpesvirales. Arch Virol. 2009;154(1):171-7.

2. Calnek BW. Marek's disease--a model for herpesvirus oncology. Crit Rev Microbiol. 1986;12(4):293-320.

3. Osterrieder N, Kamil JP, Schumacher D, Tischer BK, Trapp S. Marek's disease virus: from miasma to model. Nat Rev Microbiol. 2006;4(4):283-94.

4. Neerukonda SN, Tavlarides-Hontz P, Mccarthy F, Pendarvis K, Parcells MS. Comparison of the Transcriptomes and Proteomes of Serum Exosomes from Marek's Disease Virus-Vaccinated and Protected and Lymphoma-Bearing Chickens. Genes (Basel). 2019;10(2):116-45.

5. Witter RL. Increased virulence of Marek's disease virus field isolates. Avian Dis. 1997:41(1):149-63.

6. Rozins C, Day T. The industrialization of farming may be driving virulence evolution. Evol Appl. 2017;10(2):189-98.

7. Nair V. Spotlight on avian pathology: Marek's disease. Avian Pathol. 2018; 47(5):440-2.

8. Yu ZH, Teng M, Luo J, Wang XW, Ding K, Yu LL, Su JW, Chi JQ, Zhao P, Hu B, Zhang GP, Liu JX. Molecular characteristics and evolutionary analysis of field Marek's disease virus prevalent in vaccinated chicken flocks in recent years in China. Virus Genes. 2013;47(2):282-91.

9. Moles R. MicroRNAs-based therapy: a novel and promising strategy for Cancer treatment. Microrna. 2017;6(2):102-9.

10. Shirjang S, Mansoori B, Asghari S, Duijf PHG, Mohammadi A, Gjerstorff M, Baradaran B. MicroRNAs in cancer cell death pathways: apoptosis and necroptosis. Free Radic Biol Med. 2019;139:1-15.

11. Wang J, Wang B, Ren H, Chen W. miR-9-5p inhibits pancreatic cancer cell proliferation, invasion and glutamine metabolism by targeting GOT1. Biochem Biophys Res Commun. 2019:509(1):241-8.

12. Zhai S, Zhao L, Lin T, Wang W. Downregulation of miR-33b promotes nonsmall cell lung cancer cell growth through reprogramming glucose metabolism miR-33b regulates non-small cell lung cancer cell growth. J Cell Biochem. 2019;120(4):6651-60.

13. Subramaniam S, Jeet V, Clements JA, Gunter JH, Batra J. Emergence of MicroRNAs as key players in Cancer cell metabolism. Clin Chem. 2019;65(9): 1090-101.

14. Teng M, Yu ZH, Zhao P, Zhuang GQ, Wu ZX, Dang L, Li HZ, Ma SM, Cui ZZ, Zhang GP, Wu R, Luo J. Putative roles as oncogene or tumour suppressor of the mid-clustered microRNAs in Gallid alphaherpesvirus 2 (GaHV2) induced Marek's disease lymphomagenesis. J Gen Virol. 2017;98(5):1097-112

15. Teng M, Yu ZH, Sun AJ, Min YJ, Chi JQ, Zhao P, Su JW, Cui ZZ, Zhang GP, Luo J. The significance of the individual Meq-clustered miRNAs of Marek's disease virus in oncogenesis. J Gen Virol. 2015;96(Pt 3):637-49.
16. Yu ZH, Teng M, Sun AJ, Yu LL, Hu B, Qu LH, Ding K, Cheng XC, Liu JX, Cui ZZ, Zhang GP, Luo J. Virus-encoded miR-155 ortholog is an important potential regulator but not essential for the development of lymphomas induced by very virulent Marek's disease virus. Virology. 2014;448:55-64.

17. Chi JQ, Teng M, Yu ZH, Xu H, Su JW, Zhao P, Xing GX, Liang HD, Deng RG, Qu LH, Zhang GP, Luo J. Marek's disease virus-encoded analog of microRNA-155 activates the oncogene c-Myc by targeting LTBP1 and suppressing the TGF-beta signaling pathway. Virology. 2015;476:72-84.

18. Liu N, Jiang F, Han XY, Li M, Chen WJ, Liu QC, Liao CX, Lv YF. MiRNA-155 promotes the invasion of colorectal cancer SW-480 cells through regulating the Wnt/beta-catenin. Eur Rev Med Pharmacol Sci. 2018;22(1):101-9.

19. Liu K, Zhao K, Wang L, Sun E. Prognostic value of microRNA-155 in human carcinomas: an updated meta-analysis. Clin Chim Acta. 2018:479:171-80.

20. Hou Y, Wang J, Wang X, Shi S, Wang W, Chen Z. Appraising MicroRNA-155 as a noninvasive diagnostic biomarker for Cancer detection: a meta-analysis. Medicine (Baltimore). 2016;95(2):e2450.

21. Wu X, Chen BA. Influence of miRNA-155 on lymphoma. Zhongguo Shi Yan Xue Ye Xue Za Zhi. 2013;21(3):806-9.

22. Zhuang $G$, Sun $A$, Teng M, Luo J. A tiny RNA that packs a big punch: the critical role of a viral miR-155 Ortholog in Lymphomagenesis in Marek's disease. Front Microbiol. 2017:8:1169.

23. Zhao Y, Yao Y, Xu H, Lambeth L, Smith LP, Kgosana L, Wang X, Nair V. A functional MicroRNA-155 ortholog encoded by the oncogenic Marek's disease virus. J Virol. 2009;83(1):489-92.

24. Zhao Y, Xu H, Yao Y, Smith LP, Kgosana L, Green J, Petherbridge L, Baigent SJ, Nair V. Critical role of the virus-encoded microRNA-155 ortholog in the induction of Marek's disease lymphomas. PLoS Pathog. 2011;7(2):e1001305.

25. Zhang Y, Tang N, Luo J, Teng M, Moffat K, Shen Z, Watson M, Nair V, Yao Y. Marek's disease virus-encoded MicroRNA 155 Ortholog critical for the induction of lymphomas is not essential for the proliferation of transformed cell lines. J Virol. 2019;93(17):e00713-9.

26. Bondada MS, Yao Y, Nair V. Multifunctional miR-155 pathway in avian oncogenic virus-induced neoplastic diseases. Noncoding RNA. 2019;5(1):24-36.

27. Yao $Y$, Zhao $Y, X u H$, Smith LP, Lawrie CH, Watson M, Nair V. MicroRNA profile of Marek's disease virus-transformed T-cell line MSB-1: predominance of virus-encoded microRNAs. J Virol. 2008:82(8):4007-15.

28. Luo J, Sun AJ, Teng M, Zhou H, Cui ZZ, Qu LH, Zhang GP. Expression profiles of microRNAs encoded by the oncogenic Marek's disease virus reveal two distinct expression patterns in vivo during different phases of disease. J Gen Virol. 2011;92(Pt 3):608-20.

29. Yao Y, Zhao Y, Smith LP, Lawrie CH, Saunders NJ, Watson M, Nair V. Differential expression of microRNAs in Marek's disease virus-transformed Tlymphoma cell lines. J Gen Virol. 2009;90(Pt 7):1551-9.

30. Lian L, Qu L, Chen Y, Lamont SJ, Yang N. A systematic analysis of miRNA transcriptome in Marek's disease virus-induced lymphoma reveals novel and differentially expressed miRNAs. PLoS One. 2012;7(11):e51003.

31. Xu H, Yao Y, Smith LP, Nair V. MicroRNA-26a-mediated regulation of interleukin-2 expression in transformed avian lymphocyte lines. Cancer Cell Int. 2010;10:15-21.

32. Parnas $\mathrm{O}$, Corcoran DL, Cullen BR. Analysis of the mRNA targetome of microRNAs expressed by Marek's disease virus. MBio. 2014;5(1):e01060-13.

33. Krol J, Loedige I, Filipowicz W. The widespread regulation of microRNA biogenesis, function and decay. Nat Rev Genet. 2010;11(9):597-610.

34. Wang Y, Cong W, Wu G, Ju X, Li Z, Duan X, Wang X, Gao H. MiR-376a suppresses the proliferation and invasion of non-small-cell lung cancer by targeting c-Myc. Cell Biol Int. 2018;42(1):25-33.

35. Gu J, Lu Z, Ji C, Chen Y, Liu Y, Lei Z, Wang L, Zhang HT, Li X. Melatonin inhibits proliferation and invasion via repression of miRNA-155 in glioma cells. Biomed Pharmacother. 2017:93:969-75.

36. Wei RJ, Zhang CH, Yang WZ. MiR-155 affects renal carcinoma cell proliferation, invasion and apoptosis through regulating GSK-3beta/betacatenin signaling pathway. Eur Rev Med Pharmacol Sci. 2017;21(22):5034-41.

37. Yan Z, Che S, Wang J, Jiao Y, Wang C, Meng Q. miR-155 contributes to the progression of glioma by enhancing Wnt/beta-catenin pathway. Tumour Biol. 2015;36(7):5323-31.

38. Liu F, Song D, Wu Y, Liu X, Zhu J, Tang Y. MiR-155 inhibits proliferation and invasion by directly targeting PDCD4 in non-small cell lung cancer. Thorac Cancer. 2017;8(6):613-9.

39. Al-Haidari A, Algaber A, Madhi R, Syk I, Thorlacius H. MiR-155-5p controls colon cancer cell migration via post-transcriptional regulation of human antigen R (HuR). Cancer Lett. 2018;421:145-51. 
40. Al-Haidari AA, Syk I, Thorlacius H. MiR-155-5p positively regulates CCL17induced colon cancer cell migration by targeting RhoA. Oncotarget. 2017;8(9):14887-96.

41. Zhao XS, Han B, Zhao JX, Tao N, Dong CY. MiR-155-5p affects Wilms' tumor cell proliferation and apoptosis via targeting CREB1. Eur Rev Med Pharmacol Sci. 2019;23(3):1030-7.

42. Li S, Zhang T, Zhou X, Du Z, Chen F, Luo J, Liu Q. The tumor suppressor role of miR-155-5p in gastric cancer. Oncol Lett. 2018;16(2):2709-14.

43. Guo T, Wang XX, Fu H, Tang YC, Meng BQ, Chen CH. Early diagnostic role of PSA combined miR-155 detection in prostate cancer. Eur Rev Med Pharmacol Sci. 2018;22(6):1615-21.

44. Wang F, Shan S, Huo Y, Xie Z, Fang Y, Qi Z, Chen F, Li Y, Sun B. MiR-155-5p inhibits PDK1 and promotes autophagy via the MTOR pathway in cervical cancer. Int J Biochem Cell Biol. 2018;99:91-9.

45. Cook DN, Kang HS, Jetten AM. Retinoic Acid-Related Orphan Receptors (RORs): Regulatory Functions in Immunity, Development, Circadian Rhythm, and Metabolism. Nucl Receptor Res. 2015;2:101185-224.

46. Jetten AM, Kang HS, Takeda Y. Retinoic acid-related orphan receptors alpha and gamma: key regulators of lipid/glucose metabolism, inflammation, and insulin sensitivity. Front Endocrinol (Lausanne). 2013;4:1.

47. Sun X, Dongol S, Qiu C, Xu Y, Sun C, Zhang Z, Yang X, Zhang Q, Kong B. miR-652 promotes tumor proliferation and metastasis by targeting RORA in endometrial Cancer. Mol Cancer Res. 2018;16(12):1927-39.

48. Taheri M, Omrani MD, Noroozi R, Ghafouri-Fard S, Sayad A. Retinoic acidrelated orphan receptor alpha (RORA) variants and risk of breast cancer. Breast Dis. 2017;37(1):21-5.

49. Chang Y, Cui M, Fu X, Zhang L, Li X, Li L, Wu J, Sun Z, Zhang X, Li Z, Nan F, Yan J, Zhang M. MiRNA-155 regulates lymphangiogenesis in natural killer/Tcell lymphoma by targeting BRG1. Cancer Biol Ther. 2019;20(1):31-41.

50. Ji WG, Zhang XD, Sun XD, Wang XQ, Chang BP, Zhang MZ. miRNA-155 modulates the malignant biological characteristics of NK/T-cell lymphoma cells by ta rgeting FOXO3a gene. J Huazhong Univ Sci Technolog Med Sci. 2014;34(6):882-8.

51. Wang D, Tang M, Zong P, Liu H, Zhang T, Liu Y, Zhao Y. MiRNA-155 regulates the Th17/Treg ratio by targeting SOCS1 in severe acute pancreatitis. Front Physiol. 2018;9:686.

\section{Publisher's Note}

Springer Nature remains neutral with regard to jurisdictional claims in published maps and institutional affiliations.

Ready to submit your research? Choose BMC and benefit from:

- fast, convenient online submission

- thorough peer review by experienced researchers in your field

- rapid publication on acceptance

- support for research data, including large and complex data types

- gold Open Access which fosters wider collaboration and increased citations

- maximum visibility for your research: over $100 \mathrm{M}$ website views per year

At $\mathrm{BMC}$, research is always in progress.

Learn more biomedcentral.com/submissions 